\title{
Does the Gender of the Bully/Victim Dyad and the Type of Bullying Influence Children's Responses to a Bullying Incident?
}

\author{
Claire L. Fox ${ }^{1}$, Siân E. Jones ${ }^{2}$, Chris E. Stiff ${ }^{1}$ \& Jayde Sayers ${ }^{1}$ \\ ${ }^{1}$ School of Psychology, Keele University, UK \\ ${ }^{2}$ Department of Psychology, Oxford Brookes University, Oxford, UK
}

Corresponding author: Dr Claire Fox, School of Psychology, Keele University, Staffs. ST5 5BG. Tel: +44 (0)1782 733330, Fax: +44 (0) 1782 733387. Email: c.fox@keele.ac.uk.

Acknowledgements: We are grateful to Joanna Astle and Lindy van Vliet who provided invaluable assistance with data collection and analyses, and to the children who took part in this research, and to the school, teachers, and parents who allowed them to do so.

Current version completed $16^{\text {th }}$ December 2013 


\begin{abstract}
Children's responses to bullying are context related; they will vary depending on the specific bullying episode (Baldry, 2004). The aim of the present study was to explore whether children's responses to bullying vary depending on the gender of the bully and victim and the type of bullying portrayed. In total, 437 children aged 9-11 years from four primary schools in the UK took part in the study. Each child read a story about one child bullying another. There were twelve different versions of the story, varying the type of bullying (verbal, physical or relational/indirect) and the gender of the bully and victim (i.e. male bully female victim, female bully - male victim, male bully - male victim, female bully - female victim). Each child was randomly allocated to one of the 12 stories. After reading the story the children then responded to a series of questions to assess their perceptions of the victim and bully and situation. Overall females liked the bully more than males; females also reported liking the female victim more than the male victim and females were more likely to intervene with a female victim compared to males. The bullying was viewed as more serious, more sympathy was shown to the victim, and there was a greater likelihood of intervention when the incident involved a female bully. There was less liking for the bully if the situation involved a female victim of physical bullying. The findings are explained in terms of social identity theory and social norms about typical male and female behaviour.
\end{abstract}




\section{Does the Gender of the Bully/Victim Dyad and the Type of Bullying Influence Children's Responses to a Bullying Incident?}

Over the past 30 years a great deal of research has emerged which shows that gender has an effect on a child's experience of bullying at school (for a recent review, see Underwood \& Rosen, 2011). Less research, however, has considered how children other than the victim or bully perceive bullying incidents, depending upon the gender of those involved. This is at odds with a literature that has shown that (a) among adults, attitudes towards aggression are moulded by social factors, and (b) among children, attitudes towards bullies and their victims are context dependent (Baldry, 2004). Indeed, within the school context, social psychological factors have been shown to influence children's responses to bullying (e.g., Jones, Bombieri, Manstead \& Livingstone, 2012; Jones, Manstead, \& Livingstone, 2011). Nonetheless, much of this research has participants of one gender, or has relied upon only gender-consistent scenarios (e.g., Ojala \& Nesdale, 2004; Jones, Manstead \& Livingstone, 2009, 2011).

Here, we build upon past research by examining, in male and in female participants, how gender acts as a social psychological factor that determines children's differential reactions to bullying incidents. Research indicates that the perceptions of aggression are implicitly linked to the gender of the aggressor. Using focus groups with secondary school age students $(N=471)$, O'Brien $(2011)$ found that when presented with mixed or same gender bully-victim dyads in vignettes, the least problematic bully-victim dyad was boy-toboy. The most unacceptable dyad was a boy physically harming a girl, even in defence against the girl's bullying behaviour. Students cited gender conformity as an underlying reason for this unacceptability. However, no research has yet examined children's perceptions of different types of bullying incidents involving children in terms of the gender pairing of the bully and victim. Therefore, we examined perceptions of the bullies and victims in verbal bullying, physical bullying and relational / indirect bullying scenarios. We 
asked questions about the seriousness of the incident, likelihood of intervention, sympathy/support for the victim and liking for the victim and bully.

\section{Defining Bullying}

Bullying is commonly defined as a subset of aggressive behaviour, characterised by repetition and by an imbalance of power where the victim cannot defend him or herself for one or more reasons, for example, being outnumbered, smaller, or weaker (see Smith \& Brain, 2000). Bullying can be verbal (e.g. name-calling), physical (e.g. being kicked and punched), or indirect (also called 'relational'). Indirect bullying is defined as aggression through a third party such that the victim cannot identify the aggressor, for example, spreading rumours. Relational bullying is defined as behaviour that leads to the break-up of peer relationships (e.g. social exclusion). Boys have been found to engage in physical bullying more often than girls, but the evidence is mixed regarding gender differences in relational / indirect bullying (see Underwood, 2003 for a review of the evidence). Boys tend to be bullied by other boys, whereas girls report being bullied by both girls and boys (Whitney \& Smith, 1993). It is important to note that although same-gender bullying may be more common than cross-gender bullying, all four gender-pairing incidents (i.e. male-male, female-female, male-female and female-male) have been found to occur in schools (see Rigby, 2002). For example, both boys and girls report being physically bullied by members of the opposite sex.

\section{Children's Attitudes to Bullying}

Rigby and Slee (1991) were the first to examine children's attitudes to bullying using the 'Pro-Victim Scale'. A sample of 685 Australian school children from 6-16 years of age took part in the study. They found evidence to suggest that the majority of children display anti-bullying attitudes; they believe that bullying is wrong and are sympathetic to the plight of victims (Rigby \& Slee, 1991). These findings have been replicated in other studies 
conducted in England, Sweden and Italy (Baldry, 2004; Boulton, Bucci \& Hawker, 1999; Boulton, Trueman \& Flemington, 2002; Eslea \& Smith, 2000; Menesini et al, 1997). However, a small minority of children do seem to admire bullies and have a real lack of sympathy with the plight of children who are on the receiving end of acts of victimisation (Menesini et al, 1997; Rigby \& Slee, 1991). A common finding is that girls display stronger anti-bullying attitudes compared to boys, possibly a reflection of girls' greater capacity for empathy (Boulton et al., 1999; Rigby \& Slee, 1991). This echoes the findings from research on adults' perceptions of aggression (e.g. see Stewart-Williams, 2002).

\section{Adult Perceptions of Aggression}

Adult perceptions of aggression by males and females. Studies have examined adults' perceptions of aggression perpetrated by males and females. A consistent finding is that aggression by males is perceived as more aggressive and less acceptable compared to aggression perpetrated by females, and aggression towards females is perceived more negatively, compared to incidents in which the victim is male (Harris \& Knight-Bohnhoff, 1996). There is a wealth of evidence to suggest that domestic violence incidents in which men abuse women are rated more negatively by adults than those in which women abuse men (Sorenson \& Taylor, 2005).

Adult perceptions of different types of aggression. Further work on adults' perceptions of aggression has shown that it is not simply aggression but also the type of aggression that might be gender-stereotyped. Basow, Cahill, Phelan, Longshore and McGillicuddy-DeLisi (2007) examined young adults' perceptions of physical and relational aggression between college students. It was found that aggression by males towards females was regarded as the least acceptable. Interestingly, although physical aggression by males was rated more negatively than the same behaviour by females, the opposite pattern emerged 
for relational aggression - female relational aggression was rated as less acceptable and more harmful than relational aggression by men.

\section{Theories of Gender and Aggression}

Gender stereotypes. The findings above are explained in terms of social norms about male and female behaviour - women are perceived as weak and vulnerable (Gerber, 1991), whereas men are viewed as strong and assertive (Askew, 1989; Burr, 1998). Following from this, O’Brien (2011) found that students cited gender conformity as an underlying reason for the unacceptability of a boy physically harming a girl. However, when we take account of the type of aggression the picture becomes more complicated. It is likely that individuals consider the potential harm to the victim which might be viewed as greater when the bully engages in gender-typed aggression. Although the evidence is mixed regarding gender differences in relational aggression, people do seem to view the behaviour as more typical of girls directed towards other girls; it is often referred to as girls' aggression, with preschoolers more likely to infer that relationally aggressive characters are female (Giles \& Heyman, 2005). Furthermore, it has been suggested that the relational bullying of girls is more emotionally vindictive than boys (Adler \& Adler, 1995). Taken together, these findings could explain why gender-typed aggression is perceived as more harmful. Yet another explanation is that relationship violations for females are perceived as more negative than for males; this may be driven by the stereotype of females as more relationship oriented compared to males (Basow et al., 2007).

There is then good reason to suspect that among children, bullying by male bullies of female victims would be perceived most negatively, for example, in comparison to female bullies of male victims, because of children's understandings of social norms and gender stereotypes of male and female behaviour (i.e. males as strong and assertive and females as weak and vulnerable). It will also be important to examine interactions with bullying type; 
this hypothesis may only hold in relation to physical bullying. In contrast, the relational/indirect bullying by females may be viewed more negatively than the same behaviour by males because it is perceived as gender-normative but also potentially because relational/indirect bullying by females is indeed more emotionally vindictive.

As well as assessing perceptions of bullying incidents in general (e.g. seriousness, likelihood of intervention), we were interested in examining children's perceptions of the children involved in bullying in terms of liking. There is preliminary evidence from focus groups that male bullies of relational aggression are not popular, whereas female relational aggressors are popular (Paskewich, 2008). In addition, for girls, physical aggression appears to be more strongly related to peer rejection, compared to boys (Coie \& Dodge, 1998). Thus, we predicted that bullies engaging in behaviour that is gender counter-normative would be viewed most negatively (e.g. females who engage in physical bullying and males who engage in indirect / relational bullying). Thus, we decided to also ask questions to assess general perceptions of the targets in terms of liking since it is possible that individuals may dislike a particular bully (e.g. because the behaviour is non-gender-typed - a girl being physically aggressive) but be less likely to intervene because other factors might come into play (e.g. the risk of harm to the victim).

Gender Identification. One further factor that might have a bearing on children's perceptions of aggression in relation to gender is children's social identification with their gender category. A study by Gini (2007) revealed that children who were randomly assigned to the same class group as a bully or to the same class group as a victim of bullying prior to reading about an intergroup bullying episode attributed more blame for the bullying incident to the outgroup. For example, if the child was in the victim's group condition they would be more likely to blame the bully's class group, and vice-versa. In other words, they displayed a bias towards their ingroup. Using an innovative experimental design, Baldry (2004) varied 
the gender of the victims and bullies and whether the bully was acting alone or in a group. One hundred and seventeen students from a middle school in Italy took part in the study. Four versions of a video were created according to four different experimental conditions. In all four conditions, the gender of the bully (or bullies) was the same as the victim (male bully - male victim, female bully - female victim, male group of bullies - male victim, female group of bullies - female victim). There was evidence of same gender bias; boys blamed the male victim less than the female victim and female participants blamed the female victim less than the male victim.

\section{Present Research}

Building on Baldry's (2004) and O'Brien's (2011) studies, the present study examined children's attitudes towards bullies and victims using mixed gender pairings and same gender pairings, (i.e. male bully - male victim, male bully - female victim, female bully - male victim, female bully - female victim). Also of interest was how these attitudes might depend on the type of bullying being perpetrated and the gender of those making the judgements. Participants received one of the four pairings embedded in a scenario that described an incident of either verbal bullying, physical bullying or relational / indirect bullying (i.e., 12 different versions). As well as assessing perceptions of bullying incidents in general, we were also interested in examining children's perceptions of the children involved in the bullying. Questions measured liking for the victim and bully, sympathy/support for the victim, perceived seriousness of the bullying incident, and the participant's likelihood of intervening. The hypotheses were as follows:

(a) Girls will show more sympathy/support for victims, like victims more, bullies less, view the situation as more serious, and be more likely to intervene in comparison to boys.

(b) Bullying involving a male bully will be viewed as more serious and there will be a greater likelihood of intervention in comparison to female bullying. In addition, there will be more 
sympathy/support for the victim. This is what we predicted for physical bullying. The same predictions were made for physical bullying involving a female victim, as compared to a male victim.

(c) Females bullies will be liked less than male bullies. However, this will vary depending on the type of bullying. Females engaging in physical bullying will be liked less than male physical bullies. Males engaging in relational/indirect bullying will be liked less than female relational/indirect bullies.

(d) Children will show an in-group bias towards their own gender. Females will like victims more, bullies less, display more sympathy/support, be more likely to intervene and view the situation as more serious when the victim is female, as opposed to male. The opposite effect was predicted for males.

\section{Method}

\section{Participants}

In total, 437 pupils from eight classes across four UK schools were involved in the study, 229 were male and 208 were female. The mean age of the sample was 10.05 years ( $S D$ $=0.84$ years $)$ with children drawn from school years 5 and 6 (9-10 years and 10-11 years). The sampling strategy took into account both urban/rural status and SES profile of each school. The ethnic composition of each school (approx. 90\% white) was a reflection of the region in which the research was located. Headteachers were asked for their written consent and letters were sent home to parents giving them the option of opting their children out of the study. Seven parents did not give their consent for their children to take part and no children opted out of the research themselves.

\section{Design}


A 2 (gender of participant) $\times 3$ (type of bullying - verbal, physical, relational/indirect) $\times 2$ (gender of victim) $\times 2$ (gender of bully) fully unrelated design was used. We opted for a fully unrelated design to ensure that participants were kept blind to the aims and purposes of the study. Participants were randomly allocated to one of 12 conditions. They were presented with a verbal bullying scenario, physical bullying scenario or a relational / indirect bullying scenario involving a child bully and a child victim (see Appendix A). Commonly used names were chosen and the same name was used consistently to refer to the bully or victim (e.g. James bullying Amy, James bullying Tom, Emma bullying Tom, Emma bullying Amy).

\section{Materials}

Following each scenario, participants were asked for their views on the incident:

Liking for the victim and bully. Building on Baldry's (2004) study, two semantic differential scales were used, one for the bully and one for the victim (adapted from the PANAS; Watson, Clark \& Tellegen, 1988). Each scale consist of nine items each measuring positive and negative feelings towards the target, e.g. 'ugly-beautiful', 'boring-funny', 'weakstrong' (using a 5-point scale). A high mean score indicates more positive perceptions of the target. Cronbach's alphas for the current study were .78 for liking of the victim and .74 for liking of the bully.

Seriousness. A six-item scale developed by Basow et al. (2007) was used which asks children to consider how acceptable, aggressive and harmful they consider the behaviour to be, and how much they think $\mathrm{X}$ wants to hurt $\mathrm{Y}$, how distressed they think $\mathrm{Y}$ is and how serious the behaviour is (using a 5-point scale from 'Not at all' to 'Extremely'). Basow et al. report reliability coefficients across scenarios from .67 to .80 . A high mean score indicates that the situation was perceived as more serious. Reliability analyses identified one problematic item that was affecting the reliability of the scale ('How acceptable do you think 
X's behaviour is towards Y?'). This item was deleted to give a Cronbach's alpha with five items of .65 .

Sympathy/Support for the victim. Using existing measures (e.g. Eslea \& Smith, 2000; Rigby \& Slee, 1991; Salmivalli \& Voeten, 2004), an eight-item scale was devised to measure sympathy/support towards the victim (e.g. 'It is X's own fault that he/she is being treated in this way'), and support for intervention (e.g. 'It is a good thing to help X'). Using a four-point scale, participants were asked to indicate how much they agree with each statement $(1$ = strongly disagree, $4=$ strongly agree $)$. Three items were negatively worded and were reverse scored. A high mean score indicates greater sympathy and support $(\alpha=.71)$.

Likelihood of intervention. A single item was used to assess how likely participants would be to intervene in the situation presented to them ('How likely would you be to intervene in the situation presented above?') from Not at all (1) to Extremely (5).

\section{Procedure}

Ethical approval was obtained from the School of Psychology Ethics Committee. The researcher first explained to the class that the research was about 'things that can happen between children at school'; they would be asked to read a story and then answer some questions about the story. They were informed that they did not have to take part if they did not want to and could stop taking part at any time. Questionnaires were then distributed randomly in each class. The children were asked to then read the story and answer the questions in silence, to keep their answers private, not look at what other people were doing, and put their hand up if they required assistance. A small number of children with reading difficulties were assisted in class by a Teaching Assistant who was provided with their own copy of the questionnaire and asked to sit at a reasonable distance so that the children could keep their answers to themselves. After all the children had completed the questionnaire the children were debriefed about the purpose and aims of the study and were informed that they 
had received different stories and how they had differed. The sessions lasted from 20 to 30 minutes.

\section{Results}

\section{Intercorrelations}

Table 1 shows intercorrelations for all five dependent measures. Positive correlations were identified between sympathy/support for the victim and likelihood of intervention and between sympathy/support and seriousness, and there was a weak negative correlation between sympathy/support and liking for the bully. In addition, if the situation was viewed as more serious, the greater the likelihood of intervention and there was a negative correlation between liking for the victim and liking for the bully.

Table 1 about here

\section{MANOVA}

A 2 (gender: male versus female $\times 3$ (type of bullying: verbal versus physical versus relational/indirect) $\times 2$ (gender of victim: male versus female $) \times 2$ (gender of bully: male versus female) MANOVA was conducted taking into account all five dependent variables:

Liking for the victim, Liking for the bully, Seriousness, Sympathy/Support for the victim, and Likelihood of intervention. (see Tables 2 to 4 for means and standard deviations).

\section{Liking for the Victim}

There was a significant two-way interaction between participant gender and gender of the victim, $F(1,357)=4.28, p=.039, \mathrm{y}^{2} \mathrm{p}=.012$. Follow-up analyses identified a significant effect of gender of the victim for females only, with females reporting greater liking for the female victim, compared to the male victim, $F(1,357)=11.54, p=.001, \mathrm{y}^{2} \mathrm{p}=.031(M$ for female victim $=3.62, S D=0.85, M$ for male victim $=3.24, S D=0.73)$. 


\section{Liking for the Bully}

The MANOVA revealed a two-way interaction between type of bullying and gender of victim that approached significance, $F(2,357)=2.84, p=.060, \mathrm{y}^{2} \mathrm{p}=.016$. Simple effects analyses identified a significant effect for gender of the victim for physical bullying only $\left(F(1,357)=5.83, p=.016, \mathrm{y}^{2} \mathrm{p}=.016\right)$. There was less liking for the bully if the victim of the physical bullying was female $(M$ for female victim $=2.13, S D=0.63 ; M$ for male victim $=$ $2.41, S D=0.64)$. There was also a main effect for participant gender with females reporting greater liking for the bully, compared to males, $F(1,357)=13.27, p<.001, \mathrm{y}^{2} \mathrm{p}=.036(M$ for females $=2.43, S D=0.72 ; M$ for males $=2.17, S D=0.62$ ).

\section{Seriousness}

The analysis revealed a significant interaction between type of bullying and gender of the bully $\left(F(2,357)=3.26, p=.040, \mathrm{y}^{2} \mathrm{p}=.018\right)$. Follow-up analyses identified a significant simple effect for gender of the bully for physical bullying only, with the bullying viewed as more serious if the bully was female, $F(1,357)=10.11, p=.002, \mathrm{y}^{2} \mathrm{p}=.028(M$ for female bully $=4.33, S D=0.55, M$ for male bully $=3.93, S D=1.02$ ).

\section{Sympathy/Support for the Victim}

There was a main effect for gender of the bully with more sympathy if the bully was female, $F(1,357)=4.98, p=.026, \mathrm{y}^{2} \mathrm{p}=.014(M$ for female bully $=3.67, S D=0.38, M$ for male bully $=3.57, S D=0.46$ ).

\section{Likelihood of Intervention}

Finally, the MANOVA yielded a significant main effect for gender of the bully, $F(1,357)=5.10, p=.025, \mathrm{y}^{2} \mathrm{p}=.014(M$ for male bullies $=3.82, S D=1.16, M$ for female bullies $=4.04, S D=1.03$ ), and a two-way interaction between participant gender and gender of the victim, $F(1,357)=4.63, p=.032, \mathrm{y}^{2} \mathrm{p}=.013$. Follow-up analyses identified a significant effect of gender for the gender of the victim, with a significant difference between 
how males and females perceived female victims, $F(1,357)=4.93, p=.027, \mathrm{y}^{2} \mathrm{p}=.014(M$ for males $=3.77, S D=1.09, M$ for females $=4.13, S D=1.06)$. Females were more likely to intervene with a female victim compared to males.

\section{Discussion}

This is the first study to examine children's responses to bullying depending on the type of bullying and using same-gender and mixed-gender pairings. As Baldry (2004) notes, it is important to shed light on the conditions under which children's attitudes vary; this might help to explain some of the contradictory findings in previous studies that have assessed children's responses to bullying more generally. Similar to Baldry (2004), we found evidence of same gender bias, at least for girls. Girls reported liking the female victim more than the male victim. In addition, it was found that females were more likely to intervene with female victims compared to male participants.

It was predicted that females, given their greater capacity for empathy, would like the victim more, show more sympathy, like the bully less, view the bullying more seriously, and be more likely to intervene, compared to males. Yet, we found that females liked the bully more than males. Perhaps this is not so surprising given girls' greater capacity for empathy (Hoffman, 1977). Perhaps given the increase in anti-bullying work in schools, the divide between boys and girls in terms of anti-bullying attitudes is narrowing. Yet it may require a great level of empathy to understand the perspective of the bully and recognise that they are vulnerable too.

It is possible that some unmeasured factors may have had a bearing upon the results. Notably, children identify with their gender to different extents (David, Grace, \& Ryan, 2004). It could be that girls who identify strongly as girls were driving the effects we found, or that boys who do not identify strongly with their gender group, do empathise with the victims of bullying (see Jones, Manstead \& Livingstone, 2012). It is also possible that the 
lack of liking for the victim and bully evidenced by males might relate to their unwillingness to report such liking, rather than because males do not like victimised or bullying children. Indeed, males' lack of reported liking might in itself reflect their conformity to a social norm. Oransky and Marecek (2009) report that boys derided each other in their peer groups if they showed care or concern for others. In this vein, children's identification with their gender, and perceptions of how those of their gender should respond in bullying situations might be examined in future work.

Another surprising result was the bullying was viewed as more serious, more sympathy was shown to the victim, and there was a greater likelihood of intervention when it involved a female bully, compared to a male bully. There was good reason to suspect that among children, bullying by male bullies (particularly physical bullying) would be perceived most negatively because of children's understandings of social norms and gender stereotypes of male and female behaviour (i.e. males as strong and assertive and females as weak and vulnerable). However, as noted previously, in females, physical aggression appears to be more strongly related to peer rejection, compared to boys (Coie \& Dodge, 1998). In addition, the seminal study by Condry and Ross (1985) found that an incident where children appeared to be behaving aggressively was rated as more aggressive if it involved two girls, as opposed to two boys. They explained that this could be based on the belief that boys are more aggressive than girls which affects the judgement by either minimising the boys' aggression or inflating the degree of aggression among the girls. Thus, female bullies may be seen as unusual, given that boys are more likely to engage in bullying than girls and so perhaps children come to the conclusion that if a girl is bullying someone it must be serious. Following on from this, perhaps children are making judgements as to the motives of the female bully, e.g. they are retaliating to a previous provocation which could make the 
situation more serious. More qualitative research such as that conducted by O'Brien (2011) could help to elucidate the reasoning behind the judgements children are making.

Finally, in line with our prediction, there was evidence that children were drawing on gendered expectations with less liking for the bully if there was a female victim of physical bullying. Perhaps here the children are viewing girls as weak and vulnerable which then leads them to view the bully in a negative light.

As well as contributing to our knowledge of bullying, the research also has broader implications in addressing the question of perceptions of gender roles in children. This is the first study to examine children's perceptions of different types of bullying incidents involving children in terms of the gender pairing of the bully and victim. Our research shows that in middle childhood children are making judgements about situations based on the gender of those involved and to some extent this depends on their own gender. Future studies could examine at what age bullying-related gender biases start to emerge in children.

However, certain limitations of the study are of note. Firstly, the reliability of the seriousness scale was below the cut-off point typically deemed as acceptable. In addition, the scales used to measure liking did prove to be slightly problematic with some of the children reporting difficulty in making judgements using some of the adjective pairs, e.g. uglybeautiful; this could have reduced the sensitivity of this measure. Future studies could usefully incorporate a wider range of variables to assess children's perceptions of bullying incidents and pay careful attention to the internal reliability of the measures used. To assess liking, measures could be adapted from those used for many years to assess children's peer group acceptance, e.g. 'how much would you like to play with X?' (Asher \& Dodge, 1986).

As noted previously, it is possible that certain unmeasured factors may have influenced the results. For example, we must also be open to the idea that how participants define themselves along the dimensions of masculinity and femininity may be more 
important than their biological gender type. Research that has examined adults' perceptions of rape has found that for males (but not females), masculinity and femininity are predictive of attitudes towards rape and rape victims (Caron \& Carter, 1997). We may find that masculine males have stronger views about how males should behave with members of the opposite sex. Thus, when examining children's attitudes towards bullying incidents involving boys and girls, it will be important to assess children's gender role identities or simply children's gender identification (Jones, Manstead \& Livingstone, 2012).

We must also consider that experience of bullying may have affected children's attitudes. If a child defines themselves as a bully or victim then this may affect the judgements they make. Basow et al. found evidence that experience of particular types of aggression affected participants' perceptions of that type of aggression. Thus, as well as examining the effect of gender it will also be important in any future studies to examine any interactions with the participant's own bully/victim status.

Another point is that incidents of bullying vary in their legitimacy. Jones, Bombieri and Manstead (2012) found that assessments of the likelihood of intervention increased with decreasing legitimacy appraisals. Directly assessing legitimacy for the bullying behaviour would therefore be a welcome feature of future research.

Given the important role that teachers play in tackling bullying, it would be interesting to examine whether teachers' (as well as children's) attitudes to bullying vary depending on the gender of those involved. Previous studies have found that teachers' attitudes towards intervening vary depending on the specific context (e.g. Ellis \& Shute, 2007; Nesdale \& Pickering, 2006). Thus, it will be important to see whether gender is important and also whether the type of bullying makes a difference.

Future studies will also need to consider utilising other methods as well as vignettes, to present the different situations, such as short films using actors, as used in previous studies 
(e.g. Baldry, 2004). However, despite the criticisms of written scenarios for being low in ecological validity and thereby not reflecting 'real' attitudes and behaviours, they do enable researchers to manipulate variables in a simple yet effective way, minimising the effect of any confounding or extraneous variables.

\section{Conclusions}

The findings of the current study show that children's attitudes to bullying are context dependent, albeit not in the ways we expected. They highlight the value of a social psychological explanation of bullying. The gender of the bully and the victim in bullying incidents, in interaction with the type of bullying, had an effect on boys' and girls' perceptions of the situation. Bullying at school is an activity often carried out in view of others. The likelihood that children like the victim and bully, and would intervene depends on the gender of those involved. Thus, awareness of gender may provide a basis from which bullying can be resisted and overcome. 


\section{References}

Adler, P. A., \& Adler, P. (1995). Dynamics of inclusion and exclusion in preadolescent cliques. Social Psychology Quarterly, 58, 145-162. doi:10.2307/2787039

Asher, S. R., \& Dodge, K. A. (1986). Identifying children who are rejected by their peers. Developmental Psychology, 22, 444-449. doi:10.1037/0012-1649.22.4.444

Askew, S. (1989). Aggressive behaviour in boys: To what extent is it institutionalised? In D. P. Tattum, \& D. L. Lane (Eds.), Bullying in schools (pp. 59-72). Stoke-on-Trent: Trentham Books.

Baldry, A. C. (2004). ‘What about bullying?’ An experimental field study to understand students' attitudes towards bullying and victimisation in Italian middle schools. British Journal of Educational Psychology, 74, 583-598. doi:10.1348/0007099042376391

Basow, S. A., Cahill, K. F., Phelan, J. E., Longshore, K., \& McGillicuddy-DeLisi, A. (2007). Perceptions of relational and physical aggression among college students: Effects of gender of bully, victim and perceiver. Psychology of Women Quarterly, 31, 85-95. doi: 10.1111/j.1471-6402.2007.00333.x

Boulton, M. J., Bucci, E., \& Hawker, D. S. (1999). Swedish and English secondary school pupils' attitudes towards, and conceptions of, bullying: Concurrent links with bully/victim involvement. Scandinavian Journal of Psychology, 40, 277-284. doi:10.1111/1467-9450.404127

Boulton, M. J., Trueman, M., \& Flemington, I. (2002). Associations between secondary school pupils' definitions of bullying, attitudes towards bullying, and tendencies to engage in bullying: Age and sex differences. Educational Studies, 28, 353-370. doi:10.1080/0305569022000042390

Burr, V. (1998). Gender and social psychology. London: Routledge. 
Caron, S. L., \& Carter, D. B. (1997). The relationship among sex role orientation, egalitarianism, attitudes towards sexuality and attitudes towards violence against women. Journal of Social Psychology, 137, 568-587.

doi:10.1080/00224549709595479

Coie, J. D., \& Dodge, K. D. (1998). Aggression and anti-social behaviour. In N. Eisenberg (Ed.), Handbook of child psychology (5 ${ }^{\text {th }}$ ed., Vol. 3, pp. 779-862). New York: Wiley.

Condry, J. C. \& Ross, D. F. (1985). Sex and aggression: The influence of gender label on the perception of aggression in children. Child Development, 56, 225-233. doi:10.2307/1130189

David, B., Grace, D., \& Ryan, M.K. (2004). The gender wars: A self-categorisation perspective on the development of gender identity. In M. Bennett \& F. Sani (Eds.). Development of the social self (pp. 135-157). Hove: Psychology Press.

Ellis, A.A., \& Shute, R. (2007). Teacher responses to bullying in relation to moral orientation and seriousness of bullying. British Journal of Educational Psychology, 77, 649-63. doi:10.1348/000709906X163405

Eslea, M., \& Smith, P. K. (2000). Pupil and parent attitudes towards bullying in primary schools. European Journal of Psychology of Education, 15, 207-219. doi:10.1007/BF03173175

Gerber, G. L. (1991). Gender stereotypes and power: Perceptions of the roles in violent marriages. Sex Roles, 24, 439-258. doi:10.1007/BF00289333

Giles, J. W., \& Heyman, G. D. (2005). Young children's beliefs about the relationship between gender and aggressive behaviour. Child Development, 76, 107-121. doi:10.1111/j.1467-8624.2005.00833.x

Gini, G. (2007). Who is blameworthy? Social identity and inter-group bullying. School Psychology International, 28, 77-89. doi:10.1177/0143034307075682 
Golombok, S., \& Hines, M. (2002). Sex differences in social behaviour. In P. K. Smith, \& C. H. Hart (Eds.), Blackwell handbook of childhood social development (pp. 117-136). Cornwall, UK: Blackwell.

Harris, M. B., \& Knight-Bohnhoff, K. (1996). Gender and aggression: I. Perceptions of aggression. Sex Roles, 35, 1-26. doi:10.1007/BF01548172

Hoffman, M. L. (1977). Empathy, its development and prosocial implications. Nebraska Symposium on Motivation, 25, 169-217.

Jones, S.E., Bombieri, L., Manstead, A.S.R., \& Livingstone, A.G. (2012). The influence of norms and social identities in children's responses to bullying. British Journal of Educational Psychology, 82, 241-256. doi:10.1111/j.2044-8279.2011.02023.x

Jones, S. E., Manstead, A. S. R., \& Livingstone, A. (2009). Birds of a feather bully together: Group processes and children's responses to bullying. British Journal of Developmental Psychology, 27, 853-873. doi:10.1348/026151008X390267

Jones, S.E., Manstead, A.S.R., \& Livingstone, A.G. (2011). Ganging up or sticking together? Group processes and children's responses to bullying. British Journal of Psychology, 102, 71-96. doi:10.1348/000712610X502826

Jones, S.E., Manstead, A.S.R., \& Livingstone, A.G. (2012). Fair-weather or foul-weather friends? Group processes and children's responses to bullying. Social Psychology and Personality Science, 3, 414-420. doi:10.1177/1948550611425105

Menesini, E., Eslea, M., Smith, P. K., Genta, M. L., Giannetti, E., Fonzi, A., \& Costabile, A. (1997). Cross-national comparison of children's attitudes towards bully/victim problems in school. Aggressive Behavior, 23, 245-257. doi:10.1002/(SICI)10982337(1997)23:4<245::AID-AB3>3.0.CO;2-J

Nesdale, D., \& Pickering, K. (2006). Teachers' reactions to children's aggression. Social Development, 15, 109-127. doi: 10.1111/j.1467-9507.2006.00332.x 
O'Brien, C. (2011). Young people's comparisons of cross-gender and same-gender bullying in British secondary schools. Educational Research, 53, 257-301. doi:10.1080/00131881.2011.598658

Ojala, K., \& Nesdale, D. (2004). Bullying and social identity: The effects of group norms and distinctiveness threat on attitudes towards bullying. British Journal of Developmental Psychology, 22, 19-35. doi:10.1348/026151004772901096

Oransky, M., \& Marecek, J. (2009). "I'm not going to be a girl”. Masculinity and emotions in boys' friendships and peer groups. Journal of Adolescent Research, 24, 218-241. doi:10.1177/0743558408329951

Paskewich, B. S. (2008). Boys' perceptions and experience of relational aggression. Dissertation Abstracts International, 69(5-B).

Rigby, K. (2002). New perspectives in bullying. London: Jessica Kingsley.

Rigby, K., \& Slee, P. T. (1991). Bullying among Australian school children: Reported behaviour and attitudes towards victims. The Journal of Social Psychology, 131, 615627. doi:10.1080/00224545.1991.9924646

Salmivalli, C., \& Voeten, M. (2004). Connections between attitudes, group norms, and behaviour in bullying situations. International Journal of Behavioral Development, 28(3), 246-258. doi:10.1080/01650250344000488

Smith, P. K., \& Brain, P. (2000). Bullying in schools: Lessons from two decades of research. Aggressive Behavior, 26, 1-9. doi: 10.1002/(SICI)10982337(2000)26:1<1::AID-AB1>3.0.CO;2-7

Sorenson, S. B., \& Taylor, C. A. (2005). Female aggression towards intimate partners: An examination of social norms in a community based sample. Psychology of Women Quarterly, 29, 78-96. doi:10.1111/j.1471-6402.2005.00170.x

Stewart-Williams, S. (2002). Gender, the perception of aggression and the overestimation of 
gender bias. Sex Roles, 46, 177-189. doi:10.1023/A:1019665803317

Underwood, M. K. (2003). Social aggression among girls. New York: Guilford.

Underwood, M. K., \& Rosen, L. H. (Eds.). (2011). Social development: Relationships in infancy, childhood and adolescence. New York: Guildford.

Watson, D., Clark, L. A. \& Tellegen, A. (1988). Development and validation of brief measures of positive and negative affect: The PANAS scales. Journal of Personality and Social Psychology, 54, 1063-1070. doi:10.1037//0022-3514.54.6.1063

Whitney, I., \& Smith, P. K. (1993). A survey of the nature and extent of bullying in junior, middle and secondary schools. Educational Research, 35(1), 3-25. doi:10.1080/0013188930350101 


\section{Appendix A}

\section{Verbal Bullying Scenario}

Tom is walking down the school path on his way home. A boy called James, who is standing at the school gates, shouts really loudly as Tom walks past, saying Boo! This makes Tom lose his balance and he nearly falls over. James and Tom are in the same class. This is not the first time James has done this sort of thing to Tom. James often teases Tom and calls him nasty names. James gets other children in the class to do the same. James also threatens Tom by saying that if he won't do what he wants then he will hit him. James also makes fun of Tom's clothes and makes nasty comments about Tom's family.

\section{Physical Bullying Scenario}

Tom is walking down the school path on his way home. A boy called James, who is standing at the school gates, puts his foot out on purpose. Tom trips over, falls on the ground and rips a hole in his jumper. James kicks Tom whilst he is on the ground and laughs, a group of pupils who are standing with James laugh too. James and Tom are in the same class. This is not the first time James has done this sort of thing to Tom. James often pushes Tom around and throws things at him during lunch and in the classroom.

\section{Relational / Indirect Scenario}

James and Tom are in the same class at school. James often ignores Tom, won't speak to him or sit next to him, and gives him horrible looks. James tells the other children to do the same. James is always laughing about Tom with the other children. James asks everyone in the class to come to his party. He does not ask Tom. When teams are being picked for P.E. each week, Tom is always the last one to be picked. Tom finds out that James has been making up nasty stories about his family. 
Table 1

Intercorrelations between liking for the victim, liking for the bully, seriousness, sympathy/support for the victim, and likelihood of intervention.

Liking Victim Liking Bully $\quad$ Seriousness $\quad$ Sympathy Interv

\begin{tabular}{|c|c|c|c|c|c|}
\hline Liking victim & & & & & \\
\hline Liking Bully & $-.24 * *$ & -- & & & \\
\hline Seriousness & .05 & .02 & -- & & \\
\hline Sympathy/support & .08 & $-.11 *$ & $.37 * *$ & -- & \\
\hline Intervention & .05 & .05 & $.12 *$ & $.36 * *$ & -- \\
\hline
\end{tabular}


Table 2

Means (and SDs) for female participants by Gender of the Bully, Gender of the Victim, and Type of Bullying

\begin{tabular}{|c|c|c|c|c|c|c|c|c|c|c|c|c|}
\hline & \multicolumn{3}{|c|}{ Physical } & \multicolumn{3}{|c|}{ Verbal } & \multicolumn{3}{|c|}{ Relational/Indirect } & \multicolumn{3}{|c|}{ Overall } \\
\hline & M Victim & F Victim & Overall & M Victim & F Victim & Overall & M Victim & F Victim & Overall & M Victim & F Victim & Overall \\
\hline \multicolumn{13}{|c|}{ Liking bully } \\
\hline M Bully & $2.53(0.72)$ & $2.22(0.77)$ & $2.39(0.75)$ & $2.63(0.65)$ & $2.32(0.85)$ & $2.42(0.78)$ & $2.39(0.93)$ & $2.31(0.38)$ & $2.35(0.68)$ & $2.49(0.78)$ & $2.29(0.67)$ & $2.38(0.73)$ \\
\hline F Bully & $2.60(0.53)$ & $2.21(0.64)$ & $2.42(0.61)$ & $2.77(0.74)$ & $2.19(0.81)$ & $2.55(0.82)$ & $2.34(0.64)$ & $2.60(0.79)$ & $2.47(0.72)$ & $2.58(0.66)$ & $2.34(0.76)$ & $2.46(0.72)$ \\
\hline Overall & $2.57(0.62)$ & $2.22(0.69)$ & $2.40(0.67)$ & $2.73(0.70)$ & $2.25(0.82)$ & $2.47(0.80)$ & $2.36(0.78)$ & $2.45(0.62)$ & $2.41(0.70)$ & $2.54(0.71)$ & $2.31(0.71)$ & $2.43(0.72)$ \\
\hline \multicolumn{13}{|c|}{ Liking victim } \\
\hline M Bully & $3.39(0.62)$ & $3.60(1.22)$ & $3.48(0.92)$ & $3.00(0.61)$ & $3.74(0.80)$ & $3.50(0.81)$ & $3.04(0.96)$ & $3.62(0.55)$ & $3.35(0.80)$ & $3.17(0.76)$ & $3.66(0.85)$ & $3.44(0.84)$ \\
\hline F Bully & $3.26(0.70)$ & $3.25(0.77)$ & $3.26(0.72)$ & $3.15(0.70)$ & $3.65(0.93)$ & $3.39(0.84)$ & $3.50(0.75)$ & $3.83(0.80)$ & $3.66(0.78)$ & $3.30(0.71)$ & $3.58(0.85)$ & $3.44(0.79)$ \\
\hline Overall & $3.33(0.65)$ & $3.41(0.99)$ & $3.36(0.83)$ & $3.11(0.67)$ & $3.70(0.85)$ & $3.43(0.82)$ & $3.28(0.87)$ & $3.72(0.68)$ & $3.50(0.80)$ & $3.24(0.73)$ & $3.62(0.85)$ & $3.44(0.81)$ \\
\hline \multicolumn{13}{|l|}{ Seriousness } \\
\hline M Bully & $4.03(0.70)$ & $3.78(1.47)$ & $3.92(1.10)$ & $4.08(0.99)$ & $4.24(0.58)$ & $4.18(0.72)$ & $4.27(0.67)$ & $4.00(0.71)$ & $4.13(0.69)$ & $4.13(0.74)$ & $4.02(0.95)$ & $4.07(0.86)$ \\
\hline F Bully & $4.24(0.61)$ & $4.37(0.43)$ & $4.30(0.53)$ & $4.07(0.57)$ & $4.03(0.97)$ & $4.05(0.77)$ & $4.04(0.60)$ & $3.88(0.68)$ & $3.96(0.64)$ & $4.11(0.58)$ & $4.09(0.75)$ & $4.10(0.66)$ \\
\hline Overall & $4.13(0.66)$ & $4.10(1.07)$ & $4.12(0.87)$ & $4.07(0.70)$ & $4.13(0.79)$ & $4.10(0.75)$ & $4.15(0.63)$ & $3.94(0.69)$ & $4.04(0.67)$ & $4.12(0.65)$ & $4.05(0.85)$ & $4.09(0.76)$ \\
\hline \multicolumn{13}{|l|}{ Sympathy } \\
\hline M Bully & $3.66(0.38)$ & $3.60(0.43)$ & $3.63(0.40)$ & $3.39(0.70)$ & $3.61(0.40)$ & $3.54(0.51)$ & $3.60(0.33)$ & $3.66(0.37)$ & $3.63(0.35)$ & $3.58(0.45)$ & $3.63(0.40)$ & $3.62(0.42)$ \\
\hline F Bully & $3.73(0.26)$ & $3.76(0.30)$ & $3.74(0.28)$ & $3.56(0.46)$ & $3.76(0.26)$ & $3.65(0.39)$ & $3.55(0.50)$ & $3.62(0.41)$ & $3.60(0.45)$ & $3.61(0.42)$ & $3.71(0.33)$ & $3.66(0.38)$ \\
\hline Overall & $3.70(0.32)$ & $3.68(0.37)$ & $3.69(0.34)$ & $3.53(0.53)$ & $3.68(0.34)$ & $3.60(0.44)$ & $3.58(0.42)$ & $3.64(0.39)$ & $3.61(0.40)$ & $3.60(0.43)$ & $3.67(0.36)$ & $3.63(0.40)$ \\
\hline \multicolumn{13}{|l|}{ Intervene } \\
\hline M Bully & $4.00(1.03)$ & $3.92(1.50)$ & $3.97(1.24)$ & $3.25(1.04)$ & $4.50(0.63)$ & $4.08(0.97)$ & $3.80(1.32)$ & $4.24(0.75)$ & $4.03(1.06)$ & $3.77(1.16)$ & $4.24(0.99)$ & $4.02(1.09)$ \\
\hline F Bully & $4.00(0.89)$ & $4.07(1.28)$ & $4.03(1.08)$ & $3.89(1.32)$ & $4.13(1.03)$ & $4.00(1.18)$ & $4.06(1.06)$ & $3.88(1.09)$ & $3.97(1.06)$ & $3.98(1.10)$ & $4.02(1.11)$ & $4.00(1.10)$ \\
\hline Overall & $4.00(0.95)$ & $4.00(1.36)$ & $4.00(1.15)$ & $3.61(1.25)$ & $4.31(0.86)$ & $4.03(1.09)$ & $3.94(1.18)$ & $4.06(0.93)$ & $4.00(1.05)$ & $3.89(1.12)$ & $4.13(1.06)$ & 4.01(1.09) \\
\hline
\end{tabular}


Table 3

Means (and SDs) for male participants by Gender of the Bully, Gender of the Victim, and Type of Bullying

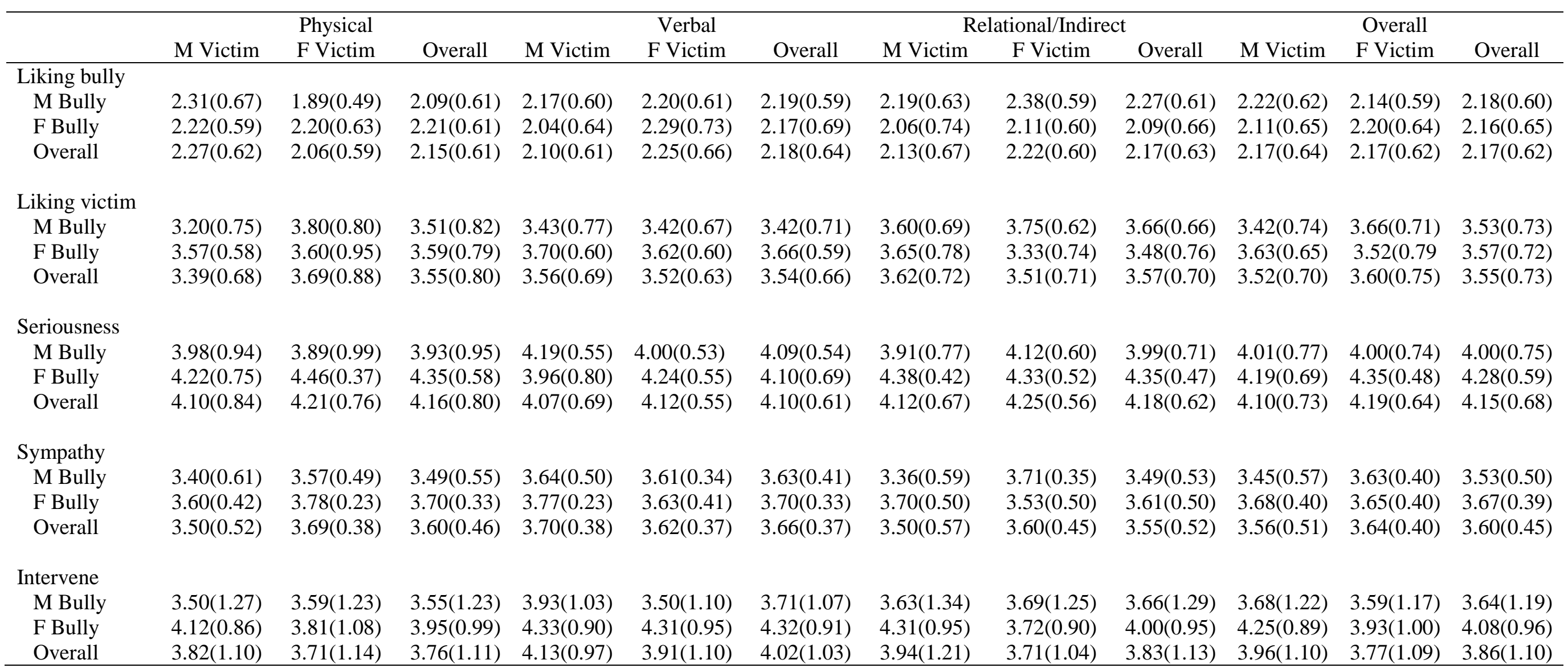


Table 4

Means (and SDs) by Gender of the Bully, Gender of the Victim, and Type of Bullying (male and female participants combined)

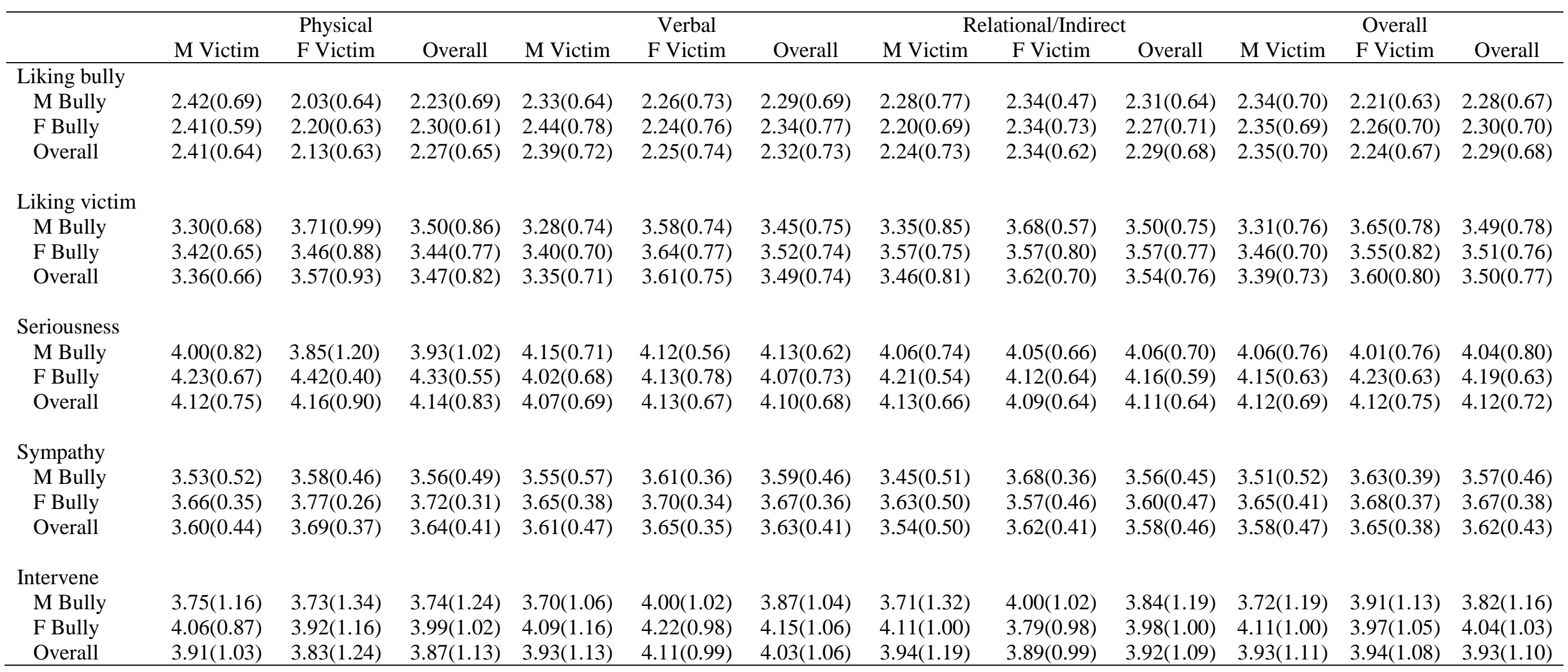

